\title{
Sapodilla (Manilkara zapota) Broth as an Alternative Media for Candida albicans
}

\author{
Chen Chui Ying, ${ }^{1}$ Ine Kuswardinah, ${ }^{2}$ Elsa Pudji Setiawati ${ }^{3}$ \\ ${ }^{1}$ Faculty of Medicine, Universitas Padjadjaran \\ ${ }^{2}$ Department of Microbiology, Faculty of Medicine, Universitas Padjadjaran \\ ${ }^{3}$ Department of Public Health, Faculty of Medicine, Universitas Padjadjaran
}

$\begin{array}{ll}\text { Abstract } & \text { Objective: To determine whether sapodilla can be used to grow Candida } \\ \text { albicans. Among all the high galactose and arabinose content fruits, the } \\ \text { sapodilla was chosen because it is available year round and can get easily in } \\ \text { market. Other than that, it also contains vitamins, calcium and phosphorus } \\ \text { which are very useful for fungi growth. } \\ \text { Methods: This study used an experimental study as a method of research. The } \\ \text { researcher culture Candida albicans on the experimental sapodilla media and } \\ \text { identifies the morphology of the fungi by using Gram staining method. The } \\ \text { experiment will be replicated two times to get accurate result. The procedure } \\ \text { of this experiment constitute of sapodilla media preparation, sapodilla media } \\ \text { observation, organism preparation, planting and incubation, observation of } \\ \text { fungal colonies and identification of the fungi. } \\ \text { Results: In 0\%, there was no fungal growth at all. In 5\%, there was mild } \\ \text { density of fungal colonies. In 10\%, there was moderate density of fungal } \\ \text { colonies and in 15\% the fungal grew with very dense colonies. }\end{array}$

\section{Introduction}

Fungi, like all other living organisms, require certain nutrients for growth. These nutrients must contain chemical elements that are constituents of the cellular materials and that are necessary for the activity of enzyme and transport systems. The main constituents of organic compounds are carbon, oxygen, hydrogen, nitrogen, sulphur and phosphorus. The remaining bioelements are metal ions such as potassium, magnesium, calcium and iron. They are required as cofactors for enzyme activity. ${ }^{1}$

\section{Correspondence:}

Chen Chui Ying, Faculty of Medicine, Universitas Padjadjaran

Jalan Raya Bandung-Sumedang Km.21 Jatinangor,

Sumedang, West Java, Indonesia

e-mail:chuiying_91@hotmail.com
Candida albicans is a normal component of the mammalian gastrointestinal flora and one of the most opportunistic pathogens in humans. Infection by this pathogen is usually found in the gastrointestinal tract because it produces an anaerobic growth condition environment. It can also be found on skin, mouth and vagina. ${ }^{2,3}$

Sabouraud dextrose agar is commonly used to support growth of fungi due to its' high glucose content. Sabouraud's dextrose agar is a selective medium which is formulated to allow growth of fungi and inhibit the growth of bacteria. Therefore, this study was initiated to offer an alternative media to support growth of fungi. The available means of inhibiting bacterial growth in Sabouraud's pre-antibiotic era was an acidic medium (pH 5.6). Another objective of the study was to discover what is the minimal concentration of sapodilla is 
needed for the growth of Candida albicans.

Fruit naturally enriched of nutrient to support the growth of fungi. Among all the high galactose and arabinose content fruits, an examination relating to sapodilla was performed. Sapodilla is regarded as a material available year round and can be obtained easily in market. ${ }^{6}$

Sapodilla, also known as Manilkara zapota, is considered as a medium-sized tree native to Central America, origin from Mexico. Sapodilla is introduced to Indonesia in the 1700s. Seeds are dark brown to black, $3 / 4$ inch long, have a smooth and shiny surface. ${ }^{7}$ Sapodilla is a main composition in making chewing gum. ${ }^{9}$

Sapodilla consist nutrients that are needed by Candida albicans for growing, such as carbohydrate and proteins. In addition, it also contains vitamins, calcium and phosphorus which are very useful for fungi growth. ${ }^{10}$

Microorganisms often grow and reproduce when minerals and sources such as energy, carbon, nitrogen, phosphorus, and sulphur are supplied. The most important environmental factors affect microbial growth are solutes and water activity, $\mathrm{pH}$, temperature,oxygen level, pressure, and radiation. ${ }^{11}$

\section{Methods}

This study used an experimental study as a research method. Culturing Candida albicans on the experimental sapodilla media and identifying the morphology of the fungi by using Gram staining method were performed. The experiment was repeated two times to get accurate result. Material used in this experiment is sapodilla media. Microbial agent used in the experiment was Candida albicans obtained from Microbiology Laboratory of Faculty of Medicine, Universitas Padjadjaran. Reagent used for Gram staining were crystal violet as a primary stain, iodine solution as a mordant,ethanol95\%asdecolourizer, safranin as a counter stain, physiological saline, oil emersion and sterile water. Controlled media used in the experiment was Sabouraud's dextrose agar. Instrument that were needed in the experiment are as following: weighing scale, test tubes, test tube rack, petri dishes, Bunsen burner, cotton swap, microscope, glass slide, $\mathrm{pH}$ indicator, inoculating loop, marking pen, toothpick and incubator. The procedure of this experiment constitute of sapodilla media preparation, sapodilla media observation, organism preparation, planting and incubation, observation of fungal colonies and identification of the fungi.

The preparation of sapodilla extract done by peeling the skin of sapodilla and it was cut into 4 pieces. The sapodilla was put into a beaker and crushed into small particles. Therefore, the extract was diluted into 4 different concentrations which were 5\%, $10 \%, 15 \%$ and aquadest which contained $0 \%$ of sapodilla extract. To get $5 \%$ concentration, $5 \mathrm{~g}$ of sapodilla extract was prepared and diluted in $100 \mathrm{~mL}$ warm water. For $10 \%$ concentration, $10 \mathrm{~g}$ of sapodilla extract was prepared and diluted in $100 \mathrm{~mL}$ of warm water, and for $15 \%, 15 \mathrm{~g}$ of sapodilla extract was prepared and diluted in $100 \mathrm{~mL}$ of warm water. The $\mathrm{pH}$ of sapodilla media was adjusted by adding $\mathrm{KOH} 40 \%$ into the media. Two gram of bacteriological agar was added into each concentration and then it was inserted into water bath. All the flask was placed into autoclave machine due to make the media sterile. The media was put into petri dish and incubated for 24 hours in $37{ }^{\circ} \mathrm{C}$. Moreover, $0.1 \mathrm{~mL}$ of $0.5 \mathrm{mF}$ contains around $300 \times 105$ $\mathrm{CFU} / \mathrm{ml}$ of Candida albicans was placed to petri dish. The petri dish was incubated for 48 hours in $37^{\circ} \mathrm{C}$.

\section{Results}

Based on the experiment performed in the study, the result showed that in $0 \%$, there was no fungal growth (Table). In 5\% concentration, there was mild density of fungal colonies. In $10 \%$ concentration, there was moderate density of fungal colonies. However, in 15\% concentration indicated that the fungal grew with very dense colonies.

All the plates showed present of fungal growth except for the $0 \%$ which contains only aquadest act as the negative control.

\section{Discussion}

A number of studies have been carried out to discover another alternative culture media to replace nutrient agar. A previous study using similar method showed that sterilized juices of vegetables and fruits can support adequate growth of Cryptococcus neoformans as well as Candida albicans. ${ }^{11}$ In addition, a study which was conducted by Deivanayaki and Iruthayaraj reported that an alternative media produced from raw vegetables can be used to cultivate microbes. ${ }^{12}$

In this study, the infusion of a hundred 
Table Fungal Growth on Sapodilla Media after 48 Hours Incubation

\begin{tabular}{lcccc}
\hline \multicolumn{1}{c}{ Concentration } & $\mathbf{0 \%}$ & $\mathbf{5 \%}$ & $\mathbf{1 0 \%}$ & $\mathbf{1 5 \%}$ \\
\hline Replication 1 & - & ++ & +++ & ++++ \\
Replication 2 & - & + & +++ & ++ \\
Replication 3 & - & ++ & +++ & +++ \\
\hline
\end{tabular}

Note: - = no colony; + = grew with small density; ++ = grew with mild density; +++ = grew with moderate density; $++++=$ grew with very dense colonies

percent concentration of Manilkara zapota was diluted with distilled water to get the remaining three concentrations, which were $5 \%, 10 \%$ and $15 \%$ to determine whether similar results could be obtained. The results showed that sapodilla broth can be an alternative media for Candida albicans. Different concentration has different fungal growth density. The higher the concentration of sapodilla extract, the greater the fungal grow.

The previous study showed that alternative media by using raw vegetables supply need nutrients. ${ }^{12}$ Both solid and liquid media of different formulations were then designed to discover the ability to grow the test organisms and compared to the growth on conventional media. Both media illustrate a good growth of fungal and bacteria. ${ }^{12}$

However, this study has several limitations due to narrow time frame to complete the whole study. The results should be further

\section{References}

1. Chanda SV, Nagani KV. Antioxidant capacity of Manilkara zapota L. leaves extracts evaluated by four in vitro methods. Nat Sci. 2010;8(10):260-6.

2. Annous BA, Fratamico PM, Smith JL. Quorum sensing in biofilms: why bacteria behave the way they do. J Food Sci. 2009;74(1):24-37.

3. Janelle MH. Sabouraud agar for fungal growth. In: Gupta VK, Tuohy MG, Ayyachamy M, Turner KM, O'Donovan A, editors. Laboratory protocols in fungal biology. $2^{\text {nd }}$ ed. New York: Springer; 2013. p. 211-6.

4. Shi J, Chinn MS, Sharma-Shivappa RR. Interactions between fungal growth, substrate utilization, and enzyme production during solid substrate cultivation of Phanerochaete chrysosporium on cotton stalks. Bioproc analyzed to determine the effectiveness of Manilkara zapota. Besides, limited access to a good facility such as in determining the actual concentration of extract, making the sapodilla extract in big amount and have to be fresh was among the problems. Other extraction method should be identified to validate the results by comparing whether similar results are obtained.

In conclusion, sapodilla (Manilkara zapota) broth has been proven in this study can be an alternative media for Candida albicans. A further study can be performed to compare the reliability for this media to be an alternative media compared to the media that used now which is sabouraud's dextrose agar. Therefore, this study also recommends other researchers to do the same experiment but with other fungi to discover the limitation of sapodilla to be a media.

Biosyst Eng. 2014;37(12):2463-73.

5. Ahn M, Yoon KC, Ryu SK, Cho NC, You IC. Clinical aspects and prognosis of mixed microbial (bacterial and fungal) keratitis. Cornea. 2011;30(4):409-13

6. Mason KL, Downward JRE, Mason KD, Falkowski NR, Eaton KA, Kao JY, et al. Candida albicans and bacterial microbiota interactions in the cecum during recolonization following broad-spectrum antibiotic therapy. Infect Immunol. 2012;80(10):3371-80.

7. Pandiyan P, Conti HR, Zheng L, Peterson AC, Mathern DR, Hernández-Santos $\mathrm{N}$, et al. CD4+ CD25+ Foxp3+ regulatory $\mathrm{T}$ cells promote Th17 cells in vitro and enhance host resistance in mouse Candida albicans Th17 cell infection model. Immunity. 2011;34(3);422-34. 
8. Woo PF, Yim HS, Khoo HE, Sia CM, Ang YK. Effects of extraction conditions on antioxidant properties of sapodilla fruit (Manilkara zapota). Food Res Int. 2013;20(5);2065-72.

9. Patel CJ, Asija S, Patel P, Dhruv M, Tyagi S. Medicated chewing gum: a modern era of novel drug delivery system. RJPDFT. 2012;4(6):293-9.

10. Willey J, Sherwood L, Woolverton C. Prescott's microbiology. $9^{\text {th }}$ ed. New York: McGraw-Hill Companies Inc; 2014.

11. Misra VC, Randhawa HS. Occurrence and significance of Cryptococcus neoformans in vegetables and fruits. Indian J Chest Dis Allied Sci. 2000;16;42(4):317-22.

12. Deivanayaki $M$, Iruthayaraj A. Alternative vegetable nutrient source for microbial growth. Int J Bio Sci. 2012;2(5):47-51. 